\title{
The concept of surrogacy in Nigeria: Issues, prospects and challenges
}

\author{
Olanike S Adelakun* \\ Lecturer, School of Law, American University of Nigeria; Doctoral Candidate, \\ University of Pretoria, South Africa
}

\section{Summary}

The journey from girlhood to womanhood in Africa begins with betrothal to marriage. This journey is not complete and the place of an African woman is not secure in her matrimonial home until such time as she is able to procreate. As such, reproduction is an essential aspect of the African family system. The inability of an African woman to fall pregnant within months of marriage is usually seen as a cause for anxiety and if this condition continues for some years, the woman is tagged barren and treated as a woman with a disability, seeing that the inability to conceive is seen as such. In most cases the husband's family mount pressure on the husband to either marry an additional wife or another wife in order to produce a child. This leads many women to make desperate decisions which may not necessarily be legally recognised, including the practice of buying babies. The article examines the legal framework for surrogacy in Nigeria. It adopts a comparative method and compares the legal frameworks governing surrogacy in Nigeria and South Africa. It concludes that there is a lacuna regarding surrogacy in the laws of Nigeria which allows for abuse during the surrogacy, and makes policy recommendations to provide the legal architecture to protect stakeholders in surrogate agreements in Nigeria.

Key words: Africa; 'baby factories'; infertility; Nigeria; surrogacy

* BL LLM (American University of Nigeria); nikegolden@yahoo.com 


\section{Introduction}

Over the past few decades the practice of surrogacy has attracted attention internationally with ongoing efforts in international legal documents to ensure best practices in surrogacy. Countries approach the subject of surrogacy from different perspectives with some countries entirely prohibiting surrogacy, ${ }^{1}$ while other countries permit surrogacy to the extent that it is not to be commercialised. ${ }^{2}$ Some countries $^{3}$ are regarded as surrogacy-friendly as they expressly allow surrogacy, while other countries have no clear regulation of surrogacy. 4

Nigeria is a multi-cultural African society which places a high value on marriage and procreation. Therefore, having a child in marriage is seen as security in the marriage and widely celebrated as the pride of womanhood and a sign of fertility. ${ }^{5}$ Research has shown that infertility is common in sub-Saharan Africa due to several factors, including sexually-transmitted infections (STIs) among men and women. ${ }^{6}$ The inadequate treatment of STIs and other infections may lead to complications and tubal damage resulting in infertility later in life. ${ }^{7}$ Some options exist, such as reproductive medicine, adoption and surrogacy to mitigate the psychological effects of infertility. However, the social stigma associated with these options prevents many Nigerians from accessing these available legal means of having children. ${ }^{8}$ The social stigma contributes to the thriving business of 'baby factories' in Nigeria, where women choose to buy babies and present them as their biological children. ${ }^{9}$

The article analyses family law in Nigeria to uncover legislative gaps in relation to surrogacy. Much is happening around the world in terms of developing laws and policies to meet the demands of citizens. Conversely, little attention is paid to the need to develop the

1 In France by arts 16-17 of the French Civil Code; in Switzerland by art 4 of Bundesgesetz über die medizinisch unterstützte Fortpflanzung 1998.

2 In England by the Surrogacy Arrangements Act 1985; in Hong Kong by Human Reproductive Technology Ordinance 2000; in South Africa by ch 19 of the Children's Act 38 of 2005.

3 In Greece by Law 3305/2005 - Enforcement of Medically Assisted Reproduction; in Israel by Embryo Carrying Agreements Law 1996; in Russia by arts 51-52 of the Family Code of Russia and art 16 of the Law on Acts on Civil Status.

4 In Nigeria based on practice guidelines of the Association of Fertility and Reproductive Health (AFRH) of Nigeria.

5 OJ Umeora, UN Nzerem \& JN Eze 'What drives grand multiparous women in rural Nigeria to seek treatment for infertility' (2013) 12 African Journal of Medical and Health Sciences 15.

6 As above.

7 OA Makinde et al 'Baby factories in Nigeria: Starting the discussion toward a national prevention policy' (2017) 18 Trauma, Violence and Abuse 98.

8 Ol Umeora et al 'Surrogacy in Nigeria: Legal, ethical, social, cultural, psychological and religious musings' (2014) 13 African Journal of Medical and Health Sciences 105 106.

$9 \quad$ Makinde et al (n 7) 99. 
Nigerian family law to accommodate the demands of the modern family in terms of developments such as complex families, surrogacy and artificial insemination. The article identifies several ways in which surrogacy is practised in Nigeria, including the consequences of and burden on the parties involved. These are blackmail, a refusal to hand over a baby after payment has been received and the rights of the parties involved in surrogacy.

The article compares the legal frameworks of Nigeria and South Africa. A justification for the choice of these jurisdictions lies in the fact that both are developing countries on the African continent. Furthermore, South Africa has a legislative framework governing surrogacy while none exists in Nigeria. The article will make recommendations for the need for regulatory policy formulation to protect the rights of parties to surrogate agreements in Nigeria. The article is divided into eight parts. Part 1 is the introduction; part 2 examines the concept and nature of surrogacy; part 3 examines the international legal framework for the regulation of surrogacy. Efforts made at the international level to regulate surrogacy is considered in this section. Part 4 analyses the regulatory framework of surrogacy in South Africa, while part 5 discusses the framework for surrogacy in Nigeria. Part 6 investigates the challenges associated with surrogacy in Nigeria. This section identifies the abuses related to surrogate agreements and practices in Nigeria. Part 7 discusses the practical solutions to solve the identified challenges of surrogacy in Nigeria, while part 8 concludes the article.

\section{Surrogacy}

Surrogate parenthood has its roots in biblical times with the relationship between Jacob, Rachael, Leah, Bilhah and Zipah and the four sons born among them. ${ }^{10}$ In the late 1970 s the first recorded case $^{11}$ of assisted reproduction through surrogacy was contested in the English courts and this development has led to several debates on surrogacy as a means of reproduction. ${ }^{12}$ Umeora defines surrogacy as a situation where a woman (third party) carries a pregnancy for the commissioning parents and hands the child over to the commissioning parents after its delivery. ${ }^{13} \mathrm{~A}$ surrogate mother is a woman who, based on an agreement before pregnancy, carries a child and relinquishes all rights to and over the child to another person after giving birth to the child. ${ }^{14}$

10 Genesis 16: 1-16 and Genesis 30: 1-13.

$11 A v$ C (1978) 8 Fam Law 170 [1985] FLR 445.

12 K Horsey \& S Sheldon 'Still hazy after all these years: The law regulating surrogacy' (2012) 20 Medical Law Review 6768.

13 Umeora et al (n 8) 106.

14 R Blauwhoff \& L Frohn 'International commercial surrogacy arrangements: The interest of the child as a concern of both human rights and private international 
Surrogacy could be either genetic (partial) or gestational (full). ${ }^{15}$ It is genetic where the male parent impregnates the surrogate mother through artificial insemination or sexual intercourse, ${ }^{16}$ while surrogacy is gestational where the male parent fertilises an egg from the female parent and the fertilised egg is placed in the womb of the surrogate mother to grow and be delivered (in vitro fertilisation). ${ }^{17}$ Surrogacy agreements can be either commercial or non-commercial (altruistic), and it could be agreed within a jurisdiction or internationally (across borders). ${ }^{18}$

The debate around the acceptability of surrogacy in many communities centres on the exploitation of those women who serve as surrogate mothers and the commercialisation of babies. ${ }^{19}$ Different countries adopted different approaches to the regulation of surrogacy. Some countries expressly prohibited surrogacy; ${ }^{20}$ some permit and regulate only non-commercial surrogacy; some countries allow all forms of surrogacy; while other countries leave surrogacy completely unregulated. ${ }^{21}$ In societies where surrogacy is allowed the consent of the surrogate mother is a yardstick to determine ethical compliance. ${ }^{22}$ The argument is that surrogacy should be considered in the same way as any other form of labour and regulation should be in form of protection against exploitation. ${ }^{23}$ However, it has been noted that a woman has a right to privacy and reproductive autonomy under international human rights law and, as such, attempts to limit these rights must be reasonably justified. ${ }^{24}$ Nigeria is among the last category of countries where surrogacy is left unregulated.

\section{International framework for surrogacy}

There is no specific international framework to regulate surrogacy, thus countries adopt suitable laws to regulate surrogate practice in their various jurisdictions. Disparities in the regulation of surrogacy

law' in C Paulussen et al (eds) Fundamental rights in international and European law (2016) 215.

15 HV MacLachlan 'Surrogate motherhood: Beyond the Warnock and the Brazier reports' (2005) 11 Human Reproduction and Genetic Ethics 3.

16 Blauwhoff \& Frohn (n 14) 215.

17 MacLachlan (n 15) 3.

18 Blauwhoff \& Frohn (n 14) 216.

19 DR Bromham 'Surrogacy: Ethical, legal and social aspects' (1995) 12 Journal of Assisted Reproduction and Genetics 509510.

20 Such as France and Switzerland (n 2).

21 A Finkelstein et al 'Surrogacy law and policy in the USL A national conversation informed by global law making' (2016) Report of the Columbia Law School Sexuality and Gender Law Clinic 11.

22 Finkelstein (n 21) 25.

23 As above.

24 J Tobin 'To prohibit or permit: What is the (human) rights response to the practice of international commercial surrogacy?' (2014) 63 International and Comparative Law Quarterly 317344. 
create conflict in cases of international surrogacy, but in such cases arguments have been in favour of the best interests of the child. ${ }^{25}$ The best interests standard may be traced to Anglo-American family law which is persistently applied problematically. ${ }^{26}$ The standard of best interests emerged from the American adoption framework that aims to establish an institution to ameliorate the condition of neglected and dependent children. ${ }^{27}$ By the twentieth century, the concept of the best interests of the child had attained a permanent position in family law and started to gain international recognition. ${ }^{28}$

The best interests of the child is a fundamental principle that underpins the practice of intercountry adoption. Both the Convention on the Rights of the Child (CRC) ${ }^{29}$ and the African Charter on the Rights and Welfare of the Child (African Children's Charter) ${ }^{30}$ embody the best interests principle as a paramount consideration in all matters relating to children. ${ }^{31}$ Similarly, the Hague Convention on Protection of Children and Cooperation in Respect of Intercountry Adoption (Hague Convention) of 1993 requires the best interests of the child in concluding that intercountry adoption is appropriate for a child. ${ }^{32}$ The courts have also supported the requirement of the best interests principle in every surrogacy arrangement dispute. ${ }^{33}$ However, nether these instruments nor the court in Labassee $v$ France gave a definition of the term 'best interests of a child'. However, the Guide to Good Practice on the Implementation of the Hague Convention (Guide) ${ }^{34}$ attributes the lack of definition of the term in the Convention to the fact that the requirements to meet the best interests of the child in individual cases vary and the factors to be considered should not be limited. ${ }^{35}$ The Guide stipulates that the term should be construed to mean the 'real' or 'true' interests of the child. ${ }^{36}$ This attempt at defining the best interests of a child only succeeded in rephrasing the

25 F Boukrouna, S Chardenoux \& C Paillassou 'International surrogacy agreements: A need for judicial cooperation?' (2015) http://www.ejtn.eu (accessed 10 June 2017).

26 LM Kohm 'Tracing the foundations of the best interests of the child standard in American jurisprudence' (2008) 11 Journal of Law and Family Studies 337347.

27 SG Post 'Adoption theologically considered' (1997) 25 Journal of Religious Ethics 149151.

28 Kohm (n 26) 350.

29 OHCHR 'Convention on the Rights of the Child' http://www.ohchr.org/EN/ Professionallnterest/Pages/CRC.aspx (accessed 19 October 2018).

30 African Charter on the Rights and Welfare of the Child OAU Doc CAB/LEG/24.9/ 49 (1990) http://www.achpr.org/instruments/child/ (accessed 19 October 2018).

31 Art 3 of CRC and art 4 of the African Children's Charter.

32 Para 4, arts 1(a), 4(b), 16(d), 21(1) \& 24 of the Hague Convention.

33 Labassee $v$ France Application 65941/11 Council of Europe: European Court of Human Rights, 26 June 2014; Mennesson v France Application 65192/11, Council of Europe: European Court of Human Rights, 26 June 2014.

34 Hague Conference on Private International Law $(\mathrm{HCCH})$ The implementation and operation of the 1993 Hague Intercountry Adoption Convention: Guide to good practice No 1 (2008).

$35 \mathrm{HCCH}$ (n 34) 15.

36 As above. 
term by using synonyms without any actual clarification on the meaning of the term. Thus, there is no agreement on the applicable yardsticks to arrive at the best interest of the child. ${ }^{37}$ As a result of this, there are varied perceptions regarding what amounts to the best interests of the child, ${ }^{38}$ and this has called for a more specific approach to regulate international surrogacy.

\subsection{Efforts at international regulation}

The Hague Convention provides a platform to regulate cross-border surrogacy using the perspective of intercountry adoption. Scholars have postulated that the regulatory procedure of the Hague Convention on adoption should be adapted to suit the demands of cross-border surrogacy arrangements. ${ }^{39}$ However, since the Hague Convention seeks to expressly regulate intercountry adoption and not international surrogacy, there is advocacy for the development of a new private international law instrument to expressly regulate surrogacy arrangements. ${ }^{40}$ Justification for this advocacy lies in the impact of international surrogacy on the operation of the Hague Convention, thus necessitating the need to review private international questions as they affect international surrogacy agreements. ${ }^{41}$ Given the cultural differences between different nations, the private international law regime seems appropriate. Based on this it was concluded at the 2010 special commission meeting on the practical operation of the Hague Convention that the use of the Hague Convention for international cases of surrogacy is inappropriate and that further research should be carried out on questions of international surrogacy. ${ }^{42}$

Reports have been presented on the issues surrounding the status of children, international surrogacy agreements and legal parentage in cases of surrogacy. In February 2016 experts on parentage and surrogacy met in The Hague where the need to consider uniformly applicable law rules was considered. No definite conclusion could be

37 N Cantwell The best interests of the child in intercountry adoption (2014) Innocenti Insights UNICEF Office of Research 5.

38 As above.

39 C Thomale 'State of play of cross-border surrogacy arrangements: Is there a case for regulatory intervention by the EU?' Paper presented at the European Parliament's Policy Hub 'Cross-border surrogacy arrangements: A need for EU action?' 16 June 2016.

$40 \mathrm{H}$ Baker 'A possible future instrument on international surrogacy arrangements: Are there lessons to be learnt from the 1993 Hague Inter-Country Adoption Convention?' in K Trimmings \& P Beaumont (eds) International surrogacy arrangements: Legal regulation at the international level (2013) 364.

$41 \mathrm{HCCH}$ 'Surrogacy - 2010 and Prior' https://www.hcch.net/en/projects/legislativeprojects/parentage-surrogacy/surrogacy-2010-and-prior (accessed 13 March 2017).

$42 \mathrm{HCCH}$ 'Conclusions and Recommendations of the 2010 Special Commission on the Practical Operation of the 1993 Hague Intercountry Adoption Convention' (2010) https://assets.hcch.net/docs/2ed33240-387f-4270-a418-d7de4ca0e464. pdf (accessed 13 March 2017). 
reached due to the complexity of surrogacy and the diverse approaches of different states. ${ }^{43}$ This is due to the fact that there are some states whose private international law requires the application of internal substantive law while some require the application of foreign law. ${ }^{44}$

The Experts' Group again met from 31 January to 3 February 2017 where the group was of the opinion that legal questions arising from legal parentage should be left to state law, including states' private international law rules, to the exclusion of matters covered by other Hague Conventions. ${ }^{45}$ The group called for additional rules and safety in international surrogacy agreements and considered the minimum standards and recognition conditions. ${ }^{46}$ The urgency of developing a binding multilateral instrument was identified, and the Experts' Group concluded on the need for further discussion on the modality of such an instrument. ${ }^{47}$ The Group explored and supported the idea of an Optional Protocol specific to international surrogacy agreements and recommended that work should continue on the development of a private international law instrument. ${ }^{48}$

\section{Framework for surrogacy in South Africa}

In South Africa surrogacy is legally recognised and regulated by Chapter 19 of the Children's Act. ${ }^{49}$ The Children's Act takes cognisance of in vitro fertilisation, and section 1 of the Act defines a surrogate agreement as

an agreement between a surrogate mother and a commissioning parent in which it is agreed that the surrogate mother will be artificially fertilised for the purpose of bearing a child for the commissioning parent and in which the surrogate mother undertakes to hand over such a child to the commissioning parent upon its birth, or within a reasonable time thereafter, with the intention that the child concerned becomes the legitimate child of the commissioning parent. ${ }^{50}$

For a surrogate agreement to be valid in South Africa, such an agreement must be in writing and signed by the parties and the surrogate mother and at least one of the commissioning parents must

$43 \mathrm{HCCH}$ 'Report of the February 2016 Meeting of the Experts' Group on Parentage/ Surrogacy' (2016) https://www.hcch.net/en/projects/legislative-projects/paren tage-surrogacy (accessed 20 October 2018).

$44 \mathrm{HCCH}(\mathrm{n} 43)$ para 10.

$45 \mathrm{HCCH}$ 'Report of the Experts' Group on the Parentage/Surrogacy Project' (2017) paras 22-23 https://www.hcch.net/en/projects/legislative-projects/parentagesurrogacy (accessed 20 October 2018). $\mathrm{HCCH}$ (n 45) paras 27-30.

$47 \mathrm{HCCH}(\mathrm{n} 45)$ para 38.

$48 \mathrm{HCCH}$ 'Report of the Experts' Group on the Parentage/Surrogacy Project' Meeting of 6-9 February 2018) paras 46-48 https://assets.hcch.net/docs/0510f196-073a4a29-a2a1-2742c95312a2.pdf (accessed 20 October 2018).

49 Act 38 of 2005.

50 Sec 1 Children's Act 38 of 2005. 
be domiciled in South Africa at the time of entering into the agreement. Such agreement must be confirmed by the High Court. 51 Where the commissioning party or the surrogate mother is married or in a permanent relationship, the Court may require the consent of the spouses or partners. ${ }^{52}$ The gametes of at least one of the commissioning parents is required by law $^{53}$ and artificial fertilisation of the surrogate mother can only be carried out within 18 months of the confirmation of the surrogate motherhood agreement by the Court. ${ }^{54}$ This points to the fact that only gestational surrogacy is permitted in South Africa. Furthermore, commercial surrogacy is expressly prohibited by section 301 of the Children's Act, and the only compensation that a surrogate mother may claim is limited to the direct expenses of artificial insemination; pregnancy; the birth of the child; loss of earnings suffered by the surrogate mother as a result of surrogacy; and insurance associated with the pregnancy. ${ }^{55}$ The permissible payments in respect of a surrogate agreement was confirmed in Ex Parte HP \& Others. ${ }^{56} \mathrm{~A}$ violation of this requirement attracts a fine or imprisonment of a maximum of 10 years or both fine and imprisonment. ${ }^{57}$

The rights of a surrogate mother in South Africa are protected, to the extent that a surrogate mother has the right to terminate the surrogate motherhood agreement within six months of giving birth to the child by filing for a notice in court. ${ }^{58}$ Where the court finds that the surrogate mother has voluntarily terminated the agreement, the court must terminate the agreement and the surrogate mother incurs no liability to the commissioning parents. ${ }^{59}$ The surrogate mother also has a right to terminate the pregnancy before delivery but she must inform the commissioning parents, and such termination ends the surrogacy agreement with the surrogate mother incurring no liability to the commissioning parents. ${ }^{60}$ Where a surrogate mother who terminates a surrogate agreement does not have a spouse, the commissioning father will share the parental responsibilities with the surrogate mother. ${ }^{61}$ This position has been criticised as contradicting the termination of the commissioning parents' rights by assigning responsibilities to the commissioning father. ${ }^{62}$

51 Sec 292 Children's Act; A Louw 'Chapter 19: Surrogate motherhood (ss 292-303)' in CJ Davel \& A Skelton (eds) Commentary on Children's Act (2018) 8.

52 Sec 293 Children's Act.

53 Sec 294 Children's Act.

54 Sec 296 Children's Act.

55 Sec 301(2) Children's Act.

562017 (4) SA 528 (GP).

57 Sec 305(6) Children's Act.

58 Sec 398(1) Children's Act.

59 Sec 298 Children's Act.

60 Sec 300 Children's Act.

61 Sec 299 Children's Act.

62 Louw (n 51) 29. 
As far as the legal status of the child is concerned, a child born out of a surrogate agreement acquires the legal status of the child of the commissioning parent(s) from the moment of birth. ${ }^{63}$ The Act protects the rights of the commissioning parents by placing an obligation on the surrogate mother to hand over the child to the commissioning parents within a reasonable time after the birth of the child. ${ }^{64}$ Thus, this section of the law gives full parental responsibility to the commissioning parents. However, this provision is subject to sections 298 and 299 of the Children's Act, as mentioned earlier.

Although the essence of the law regulating surrogacy in South Africa appears to give infertile couples or parents a chance at having their own child, the law seems to protect the rights of the surrogate mother and the child born of the surrogate agreement. There appears to be no equal protection of the rights of the commissioning parents. Moreover, the law does not provide for any compensation for the commissioning parents in a situation where the surrogate mother chooses to terminate the agreement but chooses to continue the pregnancy. ${ }^{65}$ It is important to protect the rights of the commissioning parents to the extent that they are not made vulnerable by the surrogate mother. The commissioning parents deserve the right to be free from the trauma of being outrightly denied the child at the absolute decision of the surrogate mother. There may be a need to review the law to balance the reproductive rights of the surrogate mother vis-à-vis the contractual rights of the commissioning parents.

\section{Framework for surrogacy in Nigeria}

While surrogacy is not expressly prohibited in Nigeria, it also is not legally acknowledged. As such, if a person engages in surrogate motherhood or enters into a surrogate contract in Nigeria, such a person cannot be said to have committed a crime. The underlying problem, however, is in terms of legally defining the legal parentage of the child as well as the contractual rights and duties of parties to the surrogate agreement. Presently there is no judicial pronouncement on this form of contract in Nigeria, but if a dispute arises out of a surrogate agreement and such dispute is presented before a Nigerian court, deciding such a case could prove problematic. There is a likelihood of a biased judgment based on cultural sentiments. The bias is likely to arise from socio-cultural

63 Sec 297(1) Children's Act.

64 As above.

65 The law is silent on the rights of the commissioning parents to recover any incurred cost relating to the pregnancy. 
influences which view conception through artificial means unacceptable. ${ }^{66}$

With no legislative measures to regulate surrogacy in Nigeria, most artificial reproductive technology clinics in Nigeria base their operations on the Human Fertilisation and Embryology Authority Guidelines of the United Kingdom. ${ }^{67}$ However, the Nigerian Law Reform Commission has recommended that any child born to a woman as a result of artificial insemination or implantation of an embryo in the body of a woman while she is in a marriage must be regarded as a child of the husband. ${ }^{68}$ The Commission further recommends that where a child is born under a surrogacy agreement, the commissioning parents should formally adopt the child, even if the child is the biological child of the commissioning parents. ${ }^{69}$ The rationale behind this is to prevent the surrogate mother from returning to claim the child. ${ }^{70} \mathrm{~A}$ Bill for the establishment of a Nigerian Assisted Reproduction Authority was presented before the National Assembly in 2012 and was read for the second time on 2 May 2012.71 This Bill, however, was not passed into law as it did not enjoy the support of the majority of the legislature.

Subsequently, in 2014, the National Health $\mathrm{Act}^{72}$ was enacted. Section 10 prohibits assisted reproductive technology by providing:

(1) A person shall not:

(a) manipulate any genetic material, including genetic material of human gametes, zygotes or embryos; or

(b) engage in any activity including nuclear transfer or embryo splitting for the purpose of the cloning of human being;

(c) import or export human zygotes or embryos.

(2) A person who contravenes or fails to comply with the provision of this section commits an offence and is liable on conviction to imprisonment for a minimum of five years with no option of a fine.

It may be deduced from section $10(1)(a)$ that assisted reproductive technology (ART) is prohibited. One cannot but wonder why several assisted reproductive technology practices, such as zygote intrafallopian transfer (in vitro fertilisation) and gamete intra-allopian transfers, are widely practised in major hospitals in Nigeria, including the national hospital, without any medical practitioner having been

66 AS Jegede \& AS Fayemiwo 'Cultural and ethical challenges of assisted reproductive technologies in the management of infertility among the Yoruba of South-Western Nigeria' (2010) 14 African Journal of Reproductive Health 115121.

67 JO Fadare \& AA Adeniyi 'Ethical issues in newer assisted reproductive technologies: A view from Nigeria' (2015) 18 Nigerian Journal of Clinical Practice S57 S59.

68 Law Reform Commission 'Reform of Nigerian family law' III, 15.

69 Law Reform Commission ( $\mathrm{n}$ 68) 16.

70 M Attah Family welfare law in Nigeria (2016) 215.

71 House of Representatives 'Votes and proceedings' (2 May 2012) 97 http:// nass.gov.ng/document/download/5555 (accessed 20 June 2017).

72 National Health Act 8 of 2014. 
penalised so far. However, it is worth noting that there is a pending Bill before the Nigerian Parliament to amend the National Health Act in order to regulate assisted birth technology, to encourage the safe and ethical practice of assisted reproductive technology services. ${ }^{73}$ The Bill aimed at effecting this amendment was introduced to Parliament on 8 June 2016. If passed into law, the Federal Ministry of Health will have the duty of developing policies for ART and will accredit and regulate the practice of ART. ${ }^{74}$ The training of medical personnel as well as research on assisted reproduction are stressed in the Bill. Also, reference is made to the potential vulnerabilities and health risks of potential surrogate mothers. ${ }^{75}$ Clause 60 of the Bill purports to establish a regulatory body to be known as the National Registry of Assisted Reproductive Technology Clinics and Banks in Nigeria. The national registry is to be the central database of assisted reproductive technology data in Nigeria.

The patients, surrogates and donors are required to undergo medical tests that may endanger any party to the assisted reproductive technology procedure or the child. ${ }^{76}$ ART clinics are under an obligation to provide counselling to the commissioning couple on the choices available to them and the likely consequences of the procedure, and here the international procedure such as in vitro fertilisation is recognised. ${ }^{77}$ Surrogacy is not to be considered for any commissioning mother who is able to carry a pregnancy to term, thus a commissioning mother must provide a medical report to attest to her inability to carry a pregnancy to term. ${ }^{78}$

The written consent of all parties involved in ART must be obtained by the clinic for every stage of the assisted reproduction process. ${ }^{79}$ Such consent may be withdrawn by any of the parties at any time before the human embryo or gametes are transferred to the uterus of the woman who is to carry the pregnancy. ${ }^{80}$ All clinics registered for ART will maintain records at all times of the parties and the procedure. $^{81}$

The sale of gametes outside Nigeria is expressly prohibited except where a party chooses to transfer his or her gamete outside the country, and the sale of zygotes and embryos in Nigeria is expressly prohibited. ${ }^{82}$ The option of all forms of assisted reproductive

73 A Bill for an Act to amend the National Health Act to Provide for the Regulation of Assisted Birth Technology, for Safe and Ethical Practice of Assisted Reproductive Technology Services and for other Related Matters (2016) HB 16.05.610 C 3203 http://www.placbillstrack.org/ (accessed 23 June 2017).

74 National Health Act (Amendment) Bill 2016 clause 50(1).

75 National Health Act (Amendment) Bill 2016 clause 59(2)(e)(ii).

76 National Health Act (Amendment) Bill 2016 clause 68.

77 National Health Act (Amendment) Bill 2016 clause 68(6).

78 Bill to amend the National Health Act 2016 (n 73) clause 68(10).

79 National Health Act (Amendment) Bill 2016 clause 69.

80 National Health Act (Amendment) Bill 2016 clause 69(4).

81 National Health Act (Amendment) Bill 2016 clause 70.

82 National Health Act (Amendment) Bill 2016 clause 74. 
technology, except surrogacy, is available to married infertile couples. ${ }^{83}$ This provision appears absurd. It is clear that the draftsman was not careful in the choice of words as surrogacy is the only logical solution to having a biological child by a married infertile couple, in light of the state of technology in Nigeria today. This provision appears to contradict clause 68(10) of the Bill which permits surrogacy for a woman who is unable to carry pregnancy to term or who may endanger her health by carrying a pregnancy to term. If this statute is passed in this way, the courts will be saddled with the responsibility of interpreting this provision to reflect the intention of the drafters.

As far as the rights of the parties to assisted reproduction are concerned, a gamete donor has the right to decide the extent of information to be released and to whom, except otherwise ordered by the court. ${ }^{84}$ The gamete donor must obtain the written consent of his or her spouse where married, although the rationale for this clause is not provided. One may wonder if this clause is not a breach of privacy and reproductive rights. Where a spouse chooses to donate a gamete without the knowledge of the other spouse, there should not be an impediment to this decision. Such a donor shall relinquish rights over the child or children that may be conceived using his gamete and, to this end, the identity of the recipient is not made known to the donor. ${ }^{85}$

Inasmuch as the Bill to amend the National Health Act is comprehensive in terms of procedure to regulate and ensure minimum standards in ART in Nigeria, little effort was made in the Bill to enumerate and guarantee the rights of the parties involved. There is a need to take greater effort from the human rights perspective to secure the rights of the parties to assisted reproduction as well as the child born of the procedure.

In this respect, a member of the Nigerian Parliament sponsored another Bill for an Act to provide for a National Framework for the Regulation and Supervision of Reproductive Technology and Matters Connected Therewith. ${ }^{86}$ This Bill was presented to the upper legislature (Senate) for a first reading ${ }^{87}$ on 3 November 2016 and scaled through the second reading in October 2017. The Assisted Reproductive Technology (Regulation) Bill (ART Bill) seeks to regulate ART in Nigeria. As the National Health (Amendment) Bill, the ART Bill also establishes an advisory body saddled with the responsibility of regulating and prescribing standards for assisted reproduction. ${ }^{88}$

83 National Health Act (Amendment) Bill 2016 clause 75(1).

84 National Health Act (Amendment) Bill 2016 clause 76(2).

85 National Health Act (Amendment) Bill 2016 clause 76.

86 Assisted Reproductive Technology (Regulation) Bill 2016 (ART Bill).

87 Senate of the Federal Republic of Nigeria 'Order Paper' (3 November 2016) 49 http://nass.gov.ng/document/download/8294 (accessed 20 June 2017). 
However, unlike the National Health (Amendment) Bill, chapter VII of the ART Bill specifically spells out the rights and duties of patients, donors, surrogates and children of assisted reproduction. Clause 32 of the ART Bill makes ART available to all persons, including single persons as well as married and unmarried couples. Informed consent is a prerequisite where ART is sought by couples, and a parent of a minor seeking ART will be entitled to have access to information regarding the donor, the surrogate mother and the welfare of the child to the extent permitted by law. ${ }^{89}$

Similar to the provisions of the National Health (Amendment) Bill, is the right of a gamete donor to determine the extent of information he chooses to release and his duty to relinquish all parental rights over the child that may be conceived from his gamete. ${ }^{90}$ By virtue of clause 34, commissioning parents and the surrogate mother must enter into a written agreement which is legally enforceable. ${ }^{91}$ All pregnancy-related expenses; insurance and post-natal expenses in relation to the pregnancy resulting from ART of a surrogate mother shall be borne by the commissioning parents. ${ }^{92}$ Of importance is the fact that the Bill allows a surrogate mother to accept monetary compensation from the commissioning parents for being a surrogate, ${ }^{93}$ and that a surrogate mother must relinquish all parental rights over the child. ${ }^{94}$ This clearly is different from the South African situation where commercial surrogacy is prohibited. The proposal for commercial surrogacy in Nigeria may be based on the fact that there currently is clear evidence of commercial surrogacy, ${ }^{95}$ and a bid to enact a law to prohibit this may hinder the successful support to enact the ART Bill.

To be eligible to be a surrogate mother, a woman must be between 21 and 45 years of age and no woman may act as surrogate for more than three times in her life-time. ${ }^{96}$ Likewise, no surrogate shall more than three times undergo embryo transplant for the same couple. If the embryo transplant fails, the surrogate may agree on a fresh financial agreement to undergo another transplant provided it is not in excess of the limit of three. ${ }^{97}$ A surrogate should be tested for all diseases that may endanger the child, and declare in a prescribed format that she is a surrogate and as such register for all medical

89 ART Bill clauses 32(2) and (3).

90 ART Bill clause 33.

91 Although the Bill does not make provision for any approval body before such an agreement can become effective.

92 ART Bill (n 86) clause 34(2).

93 ART Bill clause 34(3).

94 ART Bill clause 34(4).

95 E Ebhomele 'Nigerian ladies paid to get pregnant for childless couples' PM News 28 March 2013 https://www.pmnewsnigeria.com/2013/03/28/nigerian-ladiespaid-to-get-pregnant-for-childless-couples/ (accessed 11 September 2018).

96 ART Bill (n 86) clause 34(5).

97 ART Bill clause 34(9). 
procedures relating to the child. ${ }^{98} \mathrm{~A}$ surrogate may be obtained through a semen bank or by placing advertisements which must not be discriminatory in nature. ART clinics are prohibited from placing advertisements for clients to be surrogates. ${ }^{99}$

According to the Bill, the commissioning parents are legally bound to accept custody of the child, irrespective of any disability that the child or children may have, and the child should be registered in the name of the commissioning parents. A refusal to take custody of the child amounts to a crime. ${ }^{100}$ Clause $34(17)$ requires the commissioning parents to issue a certificate stating that the surrogate acted in that capacity for them. Commissioning parents may employ the services of only one surrogate at a time. ${ }^{101}$

Clause 34(19) of the Bill seeks to allow cross-border surrogacy on condition that the commissioning parent(s) outside Nigeria must employ the services of a local guardian who should take care of the surrogate mother during and after pregnancy. Such commissioning parent(s) undertake to accept custody of the child.

Marriage will be a determining factor in the status of a child born through ART. A child born to a married couple through ART is presumed the legitimate child of the couple. ${ }^{102} \mathrm{~A}$ child born to an unmarried couple through ART, with the consent of the couple, is the legitimate child of both parties. ${ }^{103}$ A child born to a single woman through ART is the legitimate child of that woman and a child born to a man through ART is the legitimate child of that man. ${ }^{104}$ On attaining the age of 18 years, a child born through ART has the right to apply for any information except the identity of his or her genetic parent(s) or surrogate mother. ${ }^{105}$ Personal information, however, may be released in the case of a medical emergency which requires physical testing of the genetic parent(s) or surrogate mother. ${ }^{106}$ Such information may only be released with the prior informed consent of the genetic parent(s) or surrogate mother.

If the ART Bill passes through Parliament it will be a significant achievement in the history of assistive reproduction in Nigeria. The ART Bill has gone a step further to supplement the provisions of the proposed National Health (Amendment) Bill by providing detailed rights and obligations of parties to the procedure.

\footnotetext{
98 ART Bill clause 34(8).

99 ART Bill clause 34(7).

100 ART Bill clauses 34(10) \& (11).

101 ART Bill clause 34(20).

102 ART Bill clause 35(1).

103 ART Bill clause 35(2).

104 ART Bill clause 35(3).

105 ART Bill clause 36(1).

106 ART Bill clause 36(3).
} 
In the absence of any legal and regulatory framework for surrogacy in Nigeria, the Human Fertilisation and Embryology $\mathrm{Act}^{107}$ of the United Kingdom is the basis of regulation of ART procedures in most ART clinics in Nigeria. The use of this law is premised on the fact that Nigeria, as a commonwealth country, has the roots of her common law in the United Kingdom. Section 45 of the Nigerian Interpretation $\mathrm{Act}^{108}$ allows statutes of general application that were in force in England on or before 1 January 1900 to be directly in force in Nigeria, so that where there is a lacuna in Nigerian law, English law may be applied. However, since there is no existing law in England before 1900 which could be applied directly to resolve disputes related to surrogacy in Nigeria, the refusal by a fertility clinic to follow the guidelines of the Human Fertilisation and Embryology Act cannot be said to be in contravention of any law. Such a law will only serve as persuasive authority and will not be binding in Nigeria.

\section{Challenges of surrogacy in Nigeria}

There are several ethical, cultural, social and legal issues surrounding surrogacy in Nigeria. Surrogacy is not a topic discussed publicly in Nigeria due to the cultural and social perceptions surrounding infertility. ${ }^{109}$ However, according to PM News, young ladies across Nigeria advertise their availability as surrogate mothers by registering on the internet ${ }^{110}$ and providing their full details and states of residence in Nigeria. ${ }^{111}$ Similarly, agencies in Nigeria advertise on the internet to match surrogate mothers with commissioning parents. ${ }^{112}$

The legal question surrounding the surrogacy agreement in Nigeria centres on the legal parentage of the child and the surrogacy agreement itself. While several countries have taken positions on surrogacy, by prohibiting, allowing without commercial value or fully allowing it with commercial value, Nigeria is yet to take a legal standpoint on the issue. ${ }^{113}$ Thus, the lack of acknowledgment of the practice of surrogacy in Nigeria has led to a lack of regulation of the practice which leaves surrogate mothers vulnerable to exploitation and commissioning parents vulnerable to blackmail.

Concerns have been expressed over abuse related to surrogacy in Nigeria. One Motunrayo Joel was reported to have posed as a young woman interested in selling her ova, and she recounted how several

107 Human Fertilisation and Embryology Act 2008 sec 59.

108 Interpretation Act Cap I23 Laws of Federation of Nigeria 2014.

109 Umeora et al (n 5) 106.

110 www.surrogatefinder.com (accessed 26 June 2017).

111 Ebhomele (n 95).

112 n 110

113 Umeora et al (n 8) 107. 
fertility clinics in Nigeria harvested ova and paid the donors. ${ }^{114}$ She reported the high rate at which Nigerian ladies sell their eggs at various fertility clinics. Her report revealed that these women were not properly counselled on the health risks involved in donating eggs, especially in cases of recurrent donation. ${ }^{115}$ Cases of quack doctors carrying out surrogacy and other in vitro fertilisation procedures have also been reported and are a cause for concern by the genuine fertility practitioners. 116

The increase in 'baby factories' has been linked to surrogacy and this has heightened the level of stigma attached to surrogacy as an option for becoming a parent. ${ }^{117}$ It has been established that the prevalence of baby factories persisting in Nigeria fulfils two needs: first, the conviction of teenage girls to give up their unwanted babies for financial gain and to avoid social stigma; and, second, the need for infertile couples to fulfil social obligations by having a baby. ${ }^{118}$ Some of the babies from these baby factories are trafficked for the purpose of international adoption or used for sacrifice at shrines. 119

The increased patronage of baby factories by infertile couples could be attributed to the social stigma publicly associated with adoption and surrogacy in Nigeria. ${ }^{120}$ The BBC reported that a common strategy for an infertile woman is to pretend to be pregnant or be fooled into believing she is pregnant, and then buying a baby from one of these baby factories. ${ }^{121}$ Makinde et $\mathrm{al}^{122}$ contend that the rapid increase in baby factory operations in Nigeria is a threat to the social acceptance of surrogacy in the country as many might be confused as to the difference between baby factories and surrogacy. ${ }^{123}$ It appears that in the case of Nigerian baby factories, while some females give their free consent, others, especially teenage

$114 \mathrm{M}$ Joel 'Ovum trading: Inside Nigeria's multi-million naira human egg business' Punch 9 August 2015 https://punchng.com/ovum-trading-inside-nigerias-multimillion-naira-human-egg-business/ (accessed 10 October 2018).

115 As above.

116 C Obinna 'Without regulation, IVF treatment is unsustainable' Vanguard 6 October 2014 https://www.vanguardngr.com/2014/10/without-regulation-ivf-treatmentunsustainable/ (accessed 10 October 2018).

117 OBA van den Akker Surrogate motherhood families (2017) 218.

118 OA Makinde et al 'Baby factories taint surrogacy in Nigeria' (2015) Reproductive BioMedicine Online 1 doi: 10.1016/j.rbmo.2015.10.001.

119 Makinde et al (n 118) 2.

120 OA Ojelabi, P Osamor \& BE Owumi 'Policies and practices of child adoption in Nigeria: A review paper' (2015) 6 Mediterranean Journal of Social Sciences 7577.

121 'Judge raises Nigeria baby selling scam concerns' BBC News 25 October 2012 http://www.bbc.com/news/uk-england-london-20082389 (accessed 20 June 2017).

122 Makinde et al (n 118) 3.

123 R Omokri 'Reno Omokri breaks silence, wants "baby factories" allowed' Premium Times 9 August 2015 http://www.premiumtimesng.com/news/headlines/188066reno-omokri-breaks-silence-wants-baby-factories-allowed.html (accessed 29 June 2017). 
girls, are coerced or forced against their wishes to be surrogate mothers. ${ }^{124}$

Omokri, however, cautioned that the criticism of surrogate mothers as being 'baby factories' by the media in Nigeria is not acceptable and should be seen as an unwelcome development. ${ }^{125}$ Omokri fails to differentiate between surrogacy-like baby factories presenting themselves as surrogate motherhood clinics. ${ }^{126}$ These threats to the development of surrogacy is a cause for concern which has led practitioners to call on government to regulate ART in Nigeria. 127

These practices of baby selling, as reported across Nigeria, contravene the Optional Protocol to the Convention on the Rights of the Child on the sale of children, child prostitution and pornography ${ }^{128}$ which Nigeria signed in 2000 and ratified in 2010. The Optional Protocol expressly prohibits the sale of children for consideration and enjoins state parties to criminalise the sale of children for sexual exploitation, the transfer of the child's organs or engagement in forced labour. ${ }^{129}$ While Nigeria has laws ${ }^{130}$ in place to comply with the Protocol, one cannot but support the enforcement mechanisms to ensure that the act of baby selling is curbed in Nigeria.

With the shift of surrogate motherhood to developing countries where surrogacy is poorly or hardly regulated, ${ }^{131}$ poverty may make women vulnerable to exploitation by entering into surrogate agreements. The incentive of earning with one agreement what a woman in a developing country may never earn in years appears too tempting to many poor women in developing countries to resist. ${ }^{132}$ In Nigeria surrogacy is not regulated, and there have been reports of young ladies either submitting themselves to or being coerced into an arrangement similar to surrogate motherhood. In view of this, it is necessary to have laws and policies that will protect the rights of

124 Makinde et al (n 118) 4.

125 Omokri (n 123).

126 OA Makinde 'Infant trafficking and baby factories: A new tale of child abuse in Nigeria' 2016 (25) Child Abuse Review 433.

127 Makinde (n 126) 433; H Umoru 'Senate moves to approve birth via in-vitro fertilisation' Vanguard 25 October 2017 https://www.vanguardngr.com/2017/10/ senate-moves-approve-birth-via-vitro-fertilization/ (accessed 10 October 2018); A Onyenucheya 'Fresh concerns over IVF babies' The Guardian 4 October 2018 https:/guardian.ng/features/health/fresh-concerns-over-ivf-babies/ (accessed 10 October 2018).

128 United Nations 'Optional Protocol to the Convention on the Rights of the Child on the Sale of Children, Child Prostitution and Pornography' (2000) A/RES/54/263 25 May 2000 http://www.ohchr.org/EN/Professionallnterest/Pages/OPSCCRC. aspx (accessed 16 June 2017).

129 Art 3 Optional Protocol to CRC on the Sale of Children.

130 Such as the Criminal Code Act Cap C38 Laws of the Federation of Nigeria 2004; the Child's Rights Act 26 of 2003; the Violence Against Persons Act 2015; and so forth.

131 M Goodwin 'Reproducing hierarchy in commercial intimacy' (2013) 88 Indiana Law Journal 12901293.

132 As above. 
parties to surrogate agreements as well as prescribing standards for the practice.

Before a surrogacy agreement is concluded, there should be a counselling session with both the surrogate mother and the commissioning parents where all parties are educated on their rights and responsibilities. A surrogate mother has the right to be fully aware of the restrictive conditions that may accompany the pregnancy, by having to refrain from certain habits such as drinking and smoking. She has the right to be aware of possible physical, emotional and hormonal changes likely to occur during pregnancy. ${ }^{133}$

The child born of a surrogate agreement is in a peculiar situation which makes his or her existence centred on a contractual formation, be it oral or written, entered into before his or her conception, although it has been argued that marriage and family are within the purview of public institutions and part of a contractual agreement with the state. ${ }^{134}$ Depending on the kind of surrogacy, the child may or may not have a genetic connection with the surrogate mother. Such a child may be faced with custody, identity or legal parentage disputes $^{135}$ of which the child is unaware. In Nigeria, where only two parents are recognised as parents to a child, ${ }^{136}$ a child born of full surrogacy is likely to face the challenge of determining the status of his or her parents, especially where all three parents involved decide to claim parentage of the child. As such, the best interests of such a child are paramount. ${ }^{137}$ Since a child could be genetically or gestationally related to the surrogate parent(s), it follows that such a child has the right to lay claim to the identity of the commissioning parents, the genetic parents as well as the surrogate parent on the strength of articles $7(1)$ and 8 of the CRC. ${ }^{138}$

\section{Surrogacy in Nigeria: The way forward}

Considering the multi-cultural diversity of Nigeria as a country, it is important to ensure that any law or policy on surrogacy takes cognisance of the nature of the country. Catholics see surrogacy as an immoral act which violates the child's dignity, while the Protestants

133 Blauwhoff \& Frohn (n 14) 228-229.

134 KM Swift 'Parenting agreements, the potential power of contract, and the limits of family law' (2007) 34 Florida State University Review 913 919-920.

135 Finkelstein (n 21) 18.

136 The Matrimonial Causes Act 18 of 1970 on custody and maintenance of a child refers to either the father or mother of a child. There is no law in Nigeria that recognises the possibility of a third parent in the concept of surrogacy, except adoptive or foster parents.

137 Finkelstein (n 21) 18.

138 Art 7(1) gives a child the right to know and be cared for by his or her parents, while art 8 enjoins state parties to respect the right of a child to preserve his or her identity, including family relations, without interference. 
display a liberal attitude towards surrogacy. ${ }^{139}$ On the cumulative strength of Quran 23: 5-7,140 70: 29-31141 and 16: $72^{142}$ on the preservation of chastity, the prohibition of inseminating one's semen into the womb of a woman who is not one's wife, gestational surrogacy, is prohibited in Islam. ${ }^{143}$

Traditional culture in Nigeria places a high value on natural conception, and rejects Western notions of surrogacy. This situation recognises the Western notion of surrogacy as a risk to destabilising family lineages which are regarded highly in Nigerian society. ${ }^{144}$ In traditional Nigerian society, the husband of an infertile wife has a choice to marry another wife and the wife of an infertile husband may choose to divorce the husband or stay with him and have children by a close relative. ${ }^{145}$ The situation is similar to that which obtains in the Zulu culture of South Africa, where the husband of an infertile wife has the right to approach the wife's family to demand a substitute who could be a sister or relative of the wife. ${ }^{146} \mathrm{~A}$ refusal to give a substitute has been described as a breach of the marriage contract in Zulu culture, and entitles the husband to a refund of the part of the bride price paid. ${ }^{147}$

A lesson could be learnt from the provisions of the Children's Act in South Africa to enact an appropriate law to regulate surrogacy in Nigeria. Nigeria already is on the right path with the National Health (Amendment) Bill 2016 and the Assistive Reproductive Technology Bill 2016. However, to avoid duplicity and a conflict in the laws, the two Bills should be harmonised with the National Health Act. ART should be recognised and efforts should be made by medical practitioners to ensure that the Bills are adopted. The ART Bill, if passed into law, will be a model for African countries. The Bill should be commended in that it goes a step further than South African law by comprehensively recognising the rights of donors, surrogate mothers, commissioning parents and the child.

139 Umeora et al (n 8) 105.

140 'And they who guard their private parts except from their wives or those their right hand possess, for indeed they will not be blamed, but whoever seeks beyond that then those are the trangressors.'

141 'And those who preserve their chastity, save with their wives and those whom their right hand possess, for thus they are not blameworthy but those who seeketh more than that, those are they who are trangressors.'

142 'And Allah hath given you wives of your own kind, and hath given you from your wives, sons and grandsons, and hath made provision of good things for you.'

$143 \mathrm{~T}$ Al-Mubarak 'Surrogacy and Islam: Between permissibility and prohibition' (2014) Islam and Civilisational Renewal 277279.

144 FT Christiana 'Surrogate motherhood: A philosophical discourse' (2013) 4 Journal of Emerging Trends in Educational Research and Policy Studies 575.

145 CS Sanders 'Surrogate motherhood and reproductive technologies: An AfricanAmerican perspective' (1992) 25 Creighton Law Review 1708.

146 FM Mahlobogwane 'Surrogate motherhood arrangements in South Africa: Changing societal norms?' (2013) 2 Speculum Juris 45.

147 TW Bennett Customary Law in South Africa (2008) 355. 


\section{Conclusion}

Nigeria is a multi-cultural and multi-religious society with a vast population. In times of increased infertility among married couples, desperate legal and illegal measures have been taken to parent a child, including the buying and selling of babies. Surrogacy is practised but left unregulated in Nigeria, making room for a series of child crimes and abuses. An analysis of the gap in the legal framework of surrogacy and artificial reproductive technology in Nigeria calls for attention and an urgent solution. While there is a dire need to regulate surrogacy in Nigeria, cognisance must be taken of the ethnical, religious and cultural values of the country. The rights of commissioning parents, surrogate mothers and unborn children must be protected by prospective laws, with priority given to the best interests of the child. Regulatory and enforcement institutions must be put in place to ensure that acceptable minimum standards are adhered to in the practice of surrogacy.

While surrogacy is a way of bringing solace to infertile couples who desire to have a biological child, like every aspect of life, surrogacy practices are accompanied by challenges. If properly regulated to protect the best interests of the child and to protect the rights of the surrogate mother and commissioning parents, surrogacy could mean an end to several illegal practices in Nigeria, such as the menace of baby factories and illegal adoption practices. 